University of Montana

ScholarWorks at University of Montana

Graduate Student Theses, Dissertations, \&

Professional Papers

1973

\title{
Conjoint-measurement analysis of human judgment
}

John Rex Painter

The University of Montana

Follow this and additional works at: https://scholarworks.umt.edu/etd

Let us know how access to this document benefits you.

\section{Recommended Citation}

Painter, John Rex, "Conjoint-measurement analysis of human judgment" (1973). Graduate Student

Theses, Dissertations, \& Professional Papers. 5026.

https://scholarworks.umt.edu/etd/5026

This Thesis is brought to you for free and open access by the Graduate School at ScholarWorks at University of Montana. It has been accepted for inclusion in Graduate Student Theses, Dissertations, \& Professional Papers by an authorized administrator of ScholarWorks at University of Montana. For more information, please contact

scholarworks@mso.umt.edu. 
A CONJOINT-MEASUREMENT ANALYSIS OF HUMAN JUDGMENT

\section{by}

John R. Painter, Jr.

B.A., University of Oregon, 1965

Presented in partial fulfillment of the requirements for the degree of

Master of Arts

UNIVERSITY OF MONTANA

1973

Approved by :

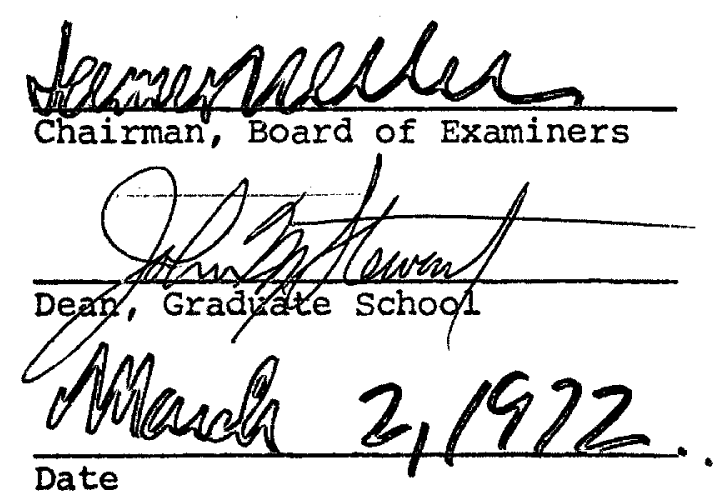


UMI Number: EP40490

All rights reserved

INFORMATION TO ALL USERS

The quality of this reproduction is dependent upon the quality of the copy submitted.

In the unlikely event that the author did not send a complete manuscript and there are missing pages, these will be noted. Also, if material had to be removed, a note will indicate the deletion.

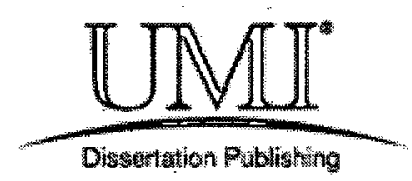

UMI EP40490

Published by ProQuest LLC (2014). Copyright in the Dissertation held by the Author. Microform Edition (C ProQuest LLC.

All rights reserved. This work is protected against unauthorized copying under Title 17, United States Code

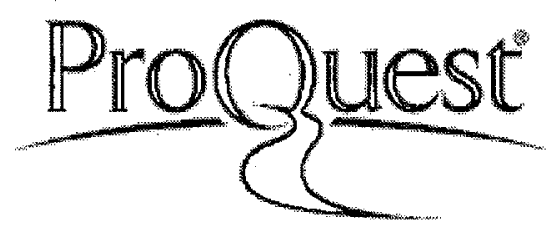

ProQuest LLC.

789 East Eisenhower Parkway

P.O. Box 1346

Ann Arbor, Ml $48106-1346$ 
AKNOWLEDGMENTS

The author extends his gratitude for the patience and support of committee members $\mathrm{Dr}$. H. A. Walters, Dr. J. P. Wollersheim, and Dr. R. McKelvey. Special thanks go to James Ullrich, committee chairman, and David Cummins, for their monumental efforts and consummate artistry in writing the Data Reduction and Polynomial Conjoint Measurement computer programs. 
TABLE OF CONTENTS

Page

LIST OF TABLES . . . . . . . . . . . . . . . . . . . iv

LIST OF FIGURES . . . . . . . . . . . . . . . . . . . v

Chapter

I. INTRODUCTION ................... 1

The Problem . . . . . . . . . . . . . . 1

Traditional Approaches . . . . . . . . . . . 4

Linear Models . . . . . . . . . . . . . . j

Configural Models . . . . . . . . . . . . 6

Polynomia1 Conjoint Measurement . . . . . . . . 12

Single Factor Independence . . . . . . . . . . . 14

Double Cancellation . . . . . . . . . . . . 15

Joint Independence . . . . . . . . . . . . . 16

Distributive Cancellation . . . . . . . . . . 17

Dual-Distributive Cancellation . . . . . . . . . 18

Purpose . . . . . . . . . . . . . . . . 19

II. METHOD . . . . . . . . . . . . . . 20

Subjects . . . . . . . . . . . . . 20

Stimuli . . . . . . . . . . . . . . 20

Procedure . . . . . . . . . . . . . . 22

III. RESULTS . . . . . . . . . . . . . . . 23

Treatment of the Data.............. 23

Critical Tests....... . . . . . . . . 26

IV. DISCUSSION . . . . . . . . . . . . 36

V. SUMMARY . . . . . . . . . . . . . . . 41

REFERENCES . . . . . . . . . . . . . . . . . 4 42

APPENDIX

A. Instructions to the subjects . . . . . . . . . 44 


\section{LIST OF TABLES}

\section{Table}

Page

1. Applicants to be ranked . . . . . . . . . . . 21

2. Consistency and intransitivity. . . . . . . . . . 25

3. Tests of single factor independence . . . . . . . . 29

4. Tests of joint independence ............. . 31

5. Summary of tests of joint independence... . . . . . 33

6. Summary of polynomial conjoint measurement tests. . . . . 34

7. Summary of composition rules. . . . . . . . . 38 


\section{IIST OF FIGURES}

Figure

Page

1. Graphic representation of the test for double cancellation . . . . . . . . . . . . . . . 16

2. Joint independence for factors $\mathrm{X}$ and $\mathrm{Y} . . . . . . . . .16$

3. Distributive cancellation ............. 17

4. Sequence of tests in the analysis of composition rules. . . . . . . . . . . . . 26 


\section{CHAPTER I}

INTRODUCTION

The Problem

Making judgments, arriving at decisions, and predicting future

outcomes are similar, highly complex cognitive operations of critical importance in human functioning. For example, physicians and clinicians make diagnoses (judgments) about patients which may have decisive impact on their lives. To understand and improve the process of judgment, it is necessary to determine whether the operations are susceptible to scientific inquiry, and then to evolve as sensitive and precise a methodology as possible. Even though judgment is unquestionably a cognitive process, thus not directly observable, it is possible and profitable to study the operations without inferring intervening variables or hypothetical constructs. To characterize the process an individual goes through in arriving at a decision, we need only describe the relationship between the information used and the decision made. Hoffman (1960, p. 117) says

- . Any realm of scientific investigation is designed to provide, among other things, a useful level of objective description. Direct observation, testing, instrumentation, and other related techniques are steps in this direction. When properly employed within a theoretical framework they seek to describe relationships between events or phenomena. The problem of describing judgment can similarly be considered to be one which interposes a set of techniques and a theoretical system between two sets of observables. Thus 
it is possible to "describe" the kinds of mental activities usually characterized as cognitive by means of mathematical models.

The two classes of events to be related in the study of the judgment process are the information available to the decision maker, and the decision itself. In making a decision, prediction, or judgment, the judge may be regarded as considering a finite set of attributes or cues (the information) and combining them in some fashion that recognizes their relative importance and the ways in which they interact. Some (e.g., Allport, 1942; Harrison, 1943) have objected to mathematical models on the grounds that they cannot hope to encompass the complex activities that lead to clinical judgments. Meehl (1954) considers this argument, and concludes that the models may in fact be satisfactory; furthermore, when the decision maker can articulate and discriminate the cues he is using and formulate the nature of the combination rule, he will be able systematically to improve his judgments and perhaps to impart this art to his students.

In judging persons or objects, each individual in the pool may be regarded as a vector of attributes: every object is rated (or at least differentiated) on each of a set of attribute dimensions; these ratings taken together determine his position relative to the other individuals being judged. For example, consider the task of a personnel manager who must screen a group of applicants for executive positions. For each applicant, he has the following data: a) intelligence; b) years of experience in related occupations; and c) achievement motivation. The decision maker may have to decide between individual $A$, who is moderately 
intelligent, has three years' experience, and is highly motivated; and individual B, highly intelligent, with six years' experience, but only average motivation. If the judge is consistent in his judgments of this nature, laws may be formulated to describe the relationship between these attributes and his ultimate decisions.

Most of the traditional approaches to the study of the judgment process require an interval scale for both the values of the attributes and for the judgment. However, almost no system of measurement in psychology approaches the requirements of an interval scale. Intelligence is one of the best-scaled of the psychological attributes, yet it appears to reflect different intervals at different points on the scale. In another example, Krantz and Tversky (1971, p. 151) discuss the relationship of drive, habit strength and incentive to response strength, and point out that

- . In general, there is no adequate independent procedure for the measurement of the relevant variables. These psychological variables (e.g., drive, incentive) are typically characterized in terms of some appropriate physical measures (e.g., hours of deprivation, magnitude of reward). This characterization may be very useful for various experimental purposes, but it provides neither a satisfactory definition nor an adequate measurement procedure, because the psychological attribute and the physically controllable variable may not be related in the proper manner. It appears rather arbitrary to assume anything more than a monotonic relation between response strength and running speed, for example... Hence, the best one can hope for is to find a monotonic relation between the controllable physical scale and the relevant psychological variable.

Although there are techniques in psychological measurement that allow establishing an interval scale for psychological attributes (see Coombs, Dawes, and Tversky, 1970; Krantz, Luce, Suppes, and Tversky, 
1971; Anderson, 1971), most studies of judgment result in data that are only ordinal. Treating these data as though they were interval may lead to serious error: for example, comparing means for ordinal data is inappropriate, since an admissible transformation of an ordinal scale may reverse the relationship between group means; defining best-fitting lines is likewise inaccurate, since an admissible transformation of scales for any of the variables will lead to an entirely different formula. Also, measures of dispersion, critical to analysis of variance and other comparison techniques, may be greatly distorted by transformations in the dependent variable.

Krantz and his associates have systematized an approach to the measurement of psychological attributes referred to as fundamental measurement. Rather than simply assuming certain distributional properties of the measurement scales and the relevant attributes, fundamental measurement determines which properties (e.g., ordinal ranking only, equal intervals, or ratios) may be assumed validly in a given system, and utilizes only these properties in treating the data. Thus, we may draw inferences about the relation between the attributes and the judgment given only ordinal data; furthermore, it is often possible to determine whether scales for both the cues and the outcome exist such that the observed ordinal relationship will hold. After a review of some traditional methods of studying judgment, one such approach will be introduced.

\section{TRADITIONAL APPROACHES}

The traditional approaches typically treat the scale values directly and draw statistical inferences by conventional tests. Thus they may 
represent means of drawing relatively stable inferences about the relationships between existing (and possibly arbitrary)measures of psychological attributes; in many cases of judgment, such relationships may be sufficient.

\section{Linear models}

The simplest class of approach to the study of judgment processes is the linear model. In such models, judges are seen as combining cues in a purely additive fashion; the relative importance of each attribute in predicting the criterion behavior is reflected in its weighting. Thus

$$
J=A_{0}+A_{1} X_{1}+A_{2} x_{2}+\ldots \cdot+A_{i} x_{i}+\ldots \cdot+A_{n} X_{n}
$$

Where $\mathrm{J}$ is the judgment, $\mathrm{x}_{i}$ is the scale value of the attribute on dimension $i$, and the $A_{i}$ are numerical weights assigned to give the best prediction. The values are numerical, although $\mathrm{J}$ can be converted to categorical judgments on the basis of cutoff scores. As Anderson (1968, p. 732) points out,

Implicit in the statement of [this equation] is the assumption that the dependent variable is numerical. . . More directly, of course, the use of such a model requires a theoretically adequate scale of measurement.

The additive model is simple and appealing as a characterization of the judgment process; the judge examines each of the attributes, weighs the importance of that attribute, and forms a judgment as the sum of the weighted attribute values. Assignment of weights to attributes is typically made on the basis of the relevance of that attribute to the performance being judged, and on its reliability. In the example introduced earlier, the personnel manager must decide, for example, whether 
intelligence is more important than years of experience and, if so, how much more weight to give it in predicting performance as an executive.

Several investigators have demonstrated that a simple additive model may be adequate in characterizing the judgment process. Hoffman (1960) utilized multiple regression techniques to determine the suitability of a linear model in judging intelligence on the basis of nine predictors. For one judge he found a regression equation that would predict judgment perfectly (when corrected for shrinkage and reliability); a different equation was almost as good for another judge. Martin (1957) determined that a linear model predicted better than a configural one for a given clinical psychologist, even though the psychologist stated that he was using an interactive strategy (in predicting "sociability" from eight selected variables from the Edwards Personal Preference schedule). Anderson (1962) found an additive model satisfactory in predicting personality impressions (likeability) formed on the basis of three adjectives describing the object, e.g., "tactful, solemn, irresponsible."

Configural models

Many clinical judgments and other complex decisions are not made by a simple summing of given cues; rather, they are made on the basis of the pattern of the cues. Profile analyses of such psychometric devices as the Minnesota Multiphasic Personality Inventory, the Edwards Personal Preference Schedule, and the Wechsler Intelligence Scales give some examples. Kirk's (1970) discussion of profile analysis of the Illinois Test of Psycholinguistic Abilities (ITPA) is typical: scale scores or sums of scores are not diagnostic in themselves, but rather in the patterns they 
form. Thus, one might suspect presence of the strausse syndrome (hyperkinesis) when both scales two and six are depressed and other scales are normal. In this case, the effect of a low score on one of the scales depends on the levels of the other scales; thus, an additive model is inappropriate. .

The most general configural model may be expressed as follows:

$$
\mathrm{J}=\mathrm{f}\left(\mathrm{x}_{1}, \mathrm{x}_{2}, \ldots, \mathrm{x}_{\mathrm{i}}, \ldots, \mathrm{x}_{\mathrm{n}}\right)
$$

where $f$ is any function defined on the $x_{i}$. A specific example is

$$
J=A_{1} X_{1}+A_{2} X_{2} X_{3}
$$

In.this illustration, attribute $x_{1}$ operates independently, while attributes $x_{2}$ and $x_{3}$ are interactive. Returning to the example of the personnel manager, suppose that his information consists of years of experience $\left(x_{1}\right)$, prestige of college $\left(x_{2}\right)$, and undergraduate grade point average $\left(\mathrm{x}_{3}\right)$. Our judge might reason that the effect of undergraduate grades depends on the prestige of the institution, since it is probably easier to get good grades at a low-quality school. Thus, he might use the strategy implied in equation [3].

Hoffman (1960) describes the interaction model as the appropriately weighted composite of all possible first-order interactions of the predictors :

$$
J=\sum_{i=2}^{n} \sum_{j=1}^{n-1} A_{i j} x_{i} x_{j} \quad(i>j)
$$

In this case, none of the cues is considered by itself; for example, the importance attached to years of experience might depend on both intelligence and quality of college attended, and importance of IQ may also vary with the prestige of the institution. 
The presence of a configural strategy in a person's judgments may be inferred by a significant discrepancy from predictability using a linear model. For example, Anderson's (1962) model of impression formation contains a term for interactive utilization of cues:

$$
J=1 / 3\left(x_{1}+x_{2}+x_{3}\right)+d+e
$$

where the $x_{i}$ are common adjectives of medium, high, or low "likeableness" value, $e$ is error, and $d$ is the discrepancy from additivity. In this case, any systematic variance not due to additivity is attributed, to nonlinear combinations of the cues, but the source of this variance, i.e., the nature of the interactions, is not directly identifiable.

Hursch and his associates (1964) likewise introduce a parameter that indicates nonlinear utilization of cues, in conjunction with Brunswik's additive lens model of the judgment process. In their formulation, positive values of the parameter indicate valid configural cue utilization, although there is no means of assessing the form of the nonlinear interaction.

Another method of assessing interaction suggested by Hoffman (1960) is the introduction of the interactive term in the regression model itself, and determining whether there is a better fit than afforded by the additive model. Sidowski and Anderson (1967) could demonstrate a significant interaction between cities and occupation preferences using such a technique.

Wiggins and Hoffman (1968) used this approach in studying clinical judgment on the basis of MMPI scale scores. Their judges, thirteen Ph.D. clinical psychologists and 16 predoctoral clinical trainees, were asked to rate MMPI profiles along an eleven-point forced normal distribution 
ranging from neurotic through neutral to psychotic. In addition to the linear model, they used the quadratic model and the sign model. The quadratic model includes the sum of weighted scale scores, plus squared scale scores, plus the first-order product of the scales. Thus,

$$
J=\sum_{i=1}^{11} A_{i} x_{i}+\sum_{i=1}^{11} A_{i} x_{i}^{2}+\sum_{i=1}^{11} \sum_{j=1}^{11} A_{i j} x_{i} x_{j} \quad(i \neq j)
$$

When the coefficients of one or more of the product terms were nonzero, and when the inclusion of these configural terms significantly improved predictability, the authors concluded that the judges were utilizing a configural strategy. The sign model also included some product terms; the same criteria were used for declaring a judge configural when the sign model predicted best.

The authors concluded that sixteen of the 29 judges could best be characterized as configural. However, the use of a configural strategy was not related to accuracy of judgment, nor to experience as a clinician. Anderson (1972) proposes that many of the findings of nonconfigural strategies result from inappropriate techniques, such as regression. He demonstrates configurality of clinical judgment by a differential weighting estimation technique, wherein the weight associated with any stimulus (in this case, statements about a mental patient's ward behavior) varies as a function of the scale value of the stimulus, as well as the other stimuIi being simultaneously considered. (Such an approach assumes an averaging strategy and is, of course, configural since the effect of any given cue depends on the other cues being considered). 
Hoffman, Slovic, and Rorer (1968) have proposed the use of the analysis of variance technique for assessing the nature of cue utilization. When the cue dimensions are orthogonal, and if levels of the attribute dimensions are considered categorical treatment factors, then the descriptive and inferential qualities of this powerful technique may be applied to the study of judgment. A significant main effect for one of the factors indicates that the decision-maker's responses varied systematically with the level of that cue dimension. Significant interaction terms indicate that the judge systematically considered patterns of cues in arriving at his judgments.

Statistical significance for a cue or pattern of cues implies only that the observed relationship occurred not as the result of chance factors (with a 1- $\alpha$ degree of certainty); it does not say anything about the strength of association between the factor or group of factors and the dependent judgment. For the latter purpose, Hoffman proposes the $\omega^{2}$ statistic (Hays, 1963), the interpretation of which is analogous to the squared product-moment correlation as a measure of proportion of variance accounted for by a given cue or pattern of cues.

Hoffman and his associates used the analysis of variance technique to evaluate the judgments a group of radiologists made concerning the malignancy of a gastric ulcer on the basis of seven dichotomous cues. The design was thus a seven-way completly crossed factorial, with two levels per factor. Aside from the discovery that judges differed rather dramatically in their use of the cues, it was determined that about ninety per cent of a judge's variation could be predicted by a simple 
additive formula, completely ignoring interactions. The value of $\omega^{2}$ for the largest interactions for judges was generally .01 or .02 , and the greatest for any of the judges was only .03. Thus, even though the experiment was designed to enhance configural cue utilization, by far the greatest proportion of the variance is accounted for by the additive model. However, the fact that there were significant interactions suggests that some judges were reliably considering patterns of the cues; it is possible that inclusion of the interactions may improve diagnostic accuracy in several cases out of a hundred, which may be worth the effort, especially in the diagnosis of malignancy. The study also indicates that judges are capable of using pattern information in a consistent fashion, even though they may not weight such factors very highly; thus it may become productive merely to train in different weighting procedures.

The ANOVA technique is limited to those situations for which all cue patterns can be orthogonally arranged within a completely crossed factorial design. Thus, the design may become unweidly where there are many cues, or where many levels of the cues are to be studied. However, if we assume highest-order interactions to be zero (that is, the n-way interaction in an n-factor design), then it is possible to eliminate within-cell replications.

Orthogonalizing cue dimensions may cause difficulties, in that such an operation may cause judges to revise their perception of the cues when the dimensions are actually correlated in nature: For example, grades and intelligence are presumably correlated to some extent; however, a 
completely crossed design in which those factors were orthogonal would demand an individual whose grades were very high, and whose intelligence was very low. The presence of such an individual might be expected to alter the judge's decision processes for the remainder of the stimuli. An additional potential objection to the ANOVA technique is that it depends heavily on the assumptions of normal distribution of error, equal within-cell variances, and error variance that is statistically independent of cell means. Nevertheless, when the assumptions can be met, and when there are adequate scales of measurement for the dependent and independent variables (which is seldom the case), analysis of variance is probably the most sensitive and descriptive of the traditional approaches to the problem.

\section{POLYNOMIAL CONJOINT MEASUREMENT}

Krantz and Tversky (1971) have developed a system for examining psychological data, referred to as polynomial conjoint measurement, that is particularly well-suited to the study of judgment. Its advantages are that it does not require interval scales for the attributes, and may be used given only a rank ordering of objects on the basis of combinations of attributes. In general,

$$
J \geq J^{\prime} \text { if and only if } f\left(x_{1}, x_{2}, \ldots . x_{n}\right) \geqslant f\left(x_{1}{ }^{\prime}, \ldots . x_{n}{ }^{\prime}\right)
$$

where $J$ is the judgment, the $x_{i}$ are attribute values, and $\geqslant$ means "is ranked at least as high as." As before, we are concerned about the function relating the attributes, $f\left(x_{i}\right)$. It turns out that we may distinguish among a broad class of functional relationships (here referred to as composition rules) solely on the basis of ordinal rankings of attri- 
bute combinations. The present paper restricts itself to the treatment of simple polynomials in three variables; ignoring permutations, they are the following: ${ }^{1}$

$$
\begin{array}{ll}
\mathrm{J}=\mathrm{X}+\mathrm{Y}+\mathrm{Z} & \text { Additive } \\
\mathrm{J}=(\mathrm{X}+\mathrm{Y}) \mathrm{Z} . & \text { Distributive } \\
\mathrm{J}=\mathrm{XY}+\mathrm{Z} & \text { Dual-distributive }
\end{array}
$$

This level of analysis is chosen because the composition rules proposed cover a great deal of psychological theory, and because the treatment of data is tractable (although the analysis is by no means trivial, as Krantz and Tversky point out [1971]).

The viability of each of the composition rules may be assessed for any ordinal matrix, provided there is a completely crossed factorial design -- that is, where each level of every attribute dimension appears with every level of the other attribute dimensions. This requirement is shared with the analysis of variance technique, and implies the same disadvantage, the potential biasing of judges' perception of attribute combinations.

The rank ordering of such a matrix must possess certain properties for any of the composition rules to hold. These properties are referred to as single-factor independence and double cancellation. In addition to these prerequisite qualities, there are properties which are implied for some of the rules, but not for others; these thus provide the discriminating function. They are joint independence, distributive cancellation,

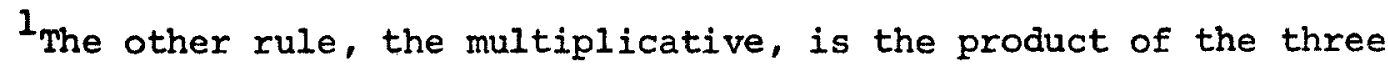
attributes. Since in the positive case it yields the additive, with a logarithmic transformation, it will not be considered separately here. 
and dual-distributive cancellation. By examining the matrix for these properties, it is possible to evaluate the feasibility of any of the composition rules for a given judge. The series of tests does not "prove" that a judge is using a specified composition rule; as Krantz and Tversky (1971, p. 172) note,

The problem investigated in this approach ... is not whether a specified functional relation holds among. several (independently measured) variables, but rather whether there exist scales of measurement (for both the dependent and the independent variables) that satisfy the proposed compostion rule.

However, if one of the composition rules is selected on the basis of polynomial conjoint measurement, it becomes possible to study the process of judgment in greater detail, and possibly to aid a judge in making better use of the information he has available. specifically, we may proceed to devise scales for both attribute and judgment dimensions that will satisfy the appropriate combination rule. Krantz and Tversky (1971, p. 153) state that

- . If the data are sufficiently regular, or finely graded (i.e., equally spaced, or dense), then the proposed diagnostic properties are not only necessary but also sufficient for the validity of the rules in question and for the construction of the appropriate numerical scales.

We turn now to a consideration of the critical tests, beginning with those satisfied by all decision rules.

\section{Single factor independence}

Single factor independence for one of the attribute dimensions demands that the rank ordering of judgments imposed by that attribute be invariant over all levels of the other two attribute dimensions. Stated 
formally, factor $X$ is independent of $Y$ and $Z$ whenever

$$
\begin{gathered}
(x, y, z) \geqslant\left(x^{\prime}, y, z\right) \text { if and only if } \\
\left(x, y^{\prime}, z^{\prime}\right) \geq\left(x^{\prime}, y^{\prime}, z^{\prime}\right)
\end{gathered}
$$

for all $x, y, z$. In this notation, $X, y$, and $z$ are attribute dimensions; $x, x^{\prime}$, and $x^{\prime \prime}$ are elements of the set of attributes $x$, etc., and $\underline{x}(x)$ will be used to denote the scale value of element $x$ in $x$. Thus, the expression within parentheses represents a vector of attributes, or one of the individuals being rank ordered.

In our example, single-factor independence corresponds to rank ordering such that, of two applicants with the same amount of experience and equal motivation, the one with the higher intelligence is always ranked higher. If this is true throughout the matrix, then IQ is independent of experience and motivation. In terms of the ordinal matrix, single-factor independence for $x$ requires that the elements of that set stand in the same relationship to one another over all levels of the other factors. Thus, the entries in any given $\mathrm{X}$-row or $\mathrm{Y}$-column are ordered in the same way as they are in any corresponding space.

\section{Double Cancellation}

The next quality implied for all composition rules is double cancellation. $X$ and $Y$ satisfy double cancellation if

$$
\begin{aligned}
\left(x, y^{\prime}, z\right) & \geq\left(x^{\prime}, y^{\prime \prime}, z\right) \\
\text { and }\left(x^{\prime}, y, z\right) & \geqslant\left(x^{\prime \prime}, y^{\prime}, z\right) \\
\text { imply }(x, y, z) & \geq\left(x^{\prime \prime}, y^{\prime \prime}, z\right)
\end{aligned}
$$

for all $x, y, z$. Thus, this test is performed in every $3 \times 3$ submatrix of the judgments. Graphically represented in Figure 1, the antecedents 
are single arrows, and the implication is double.

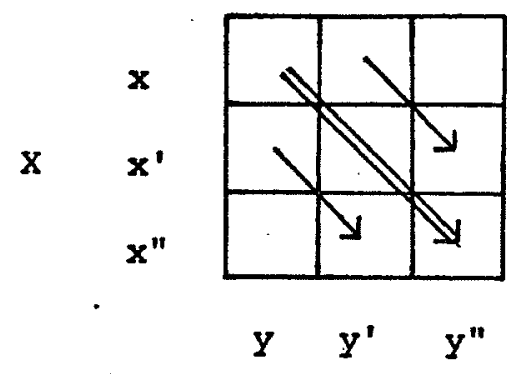

Fig. 1. Graphic representation of the test for double cancellation. Single arrows represent antecedents; the implication is double.

\section{Joint Independence}

$X$ and $Y$ are said to be jointly independent of $Z$ whenever

$$
(x, y, z) \geq\left(x^{\prime}, y^{\prime}, z\right) \text { iff }\left(x, y, z^{\prime}\right) \geq\left(x^{\prime}, y^{\prime}, z^{\prime}\right)
$$

for all $x, y, z$. This is equivalent to the conclusion that the joint effect of the combination $x, y$ is always at least as great as the effect of $x^{\prime}, y^{\prime}$ for all levels of $z$. This corresponds to the property that endpoints of parallel diagonals are ordered in the same way.

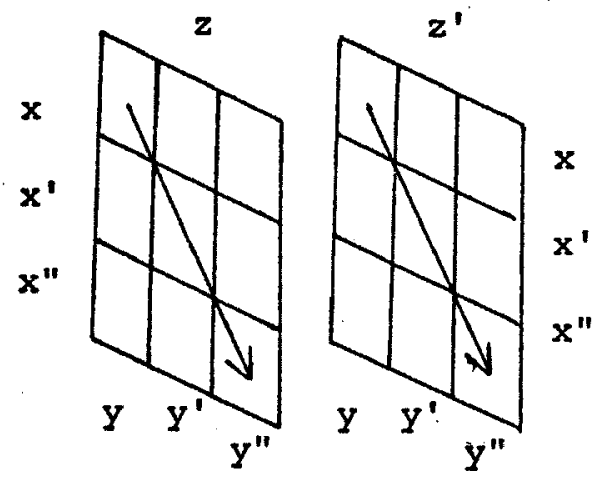

Fig. 2. Joint independence for factors $X$ and $Y$. 
Joint independence is not implied for all pairs of factors in all composition rules. In the case of the additive rule, all pairs of factors are jointly independent. If no pair is jointly independent, then no simple polynomial in the unsigned case is appropriate; and if one or two pairs are jointly independent, then either the distributive or the dual-distributive rule might hold.

\section{Distributive Cancellation}

Distributive cancellation is satisfied whenever

$$
\begin{aligned}
& (x, y, z) \geq\left(x^{\prime \prime}, y^{\prime \prime}, z^{\prime}\right) \\
& \left(x^{\prime}, y^{\prime}, z\right) \geq\left(x^{\prime \prime}, y^{\prime}{ }^{\prime}, z^{\prime}\right)
\end{aligned}
$$

and $\left(x^{\prime \prime} ', y^{\prime \prime}, z^{\prime}\right) \geqslant\left(x^{\prime}, y, z\right)$

imply $\left(x, y^{\prime}, z\right) \geq\left(x^{\prime \prime}, y^{\prime \prime}, z^{\prime}\right)$

This property may likewise be tested by consideration of parallel diagonals (Figure 3).

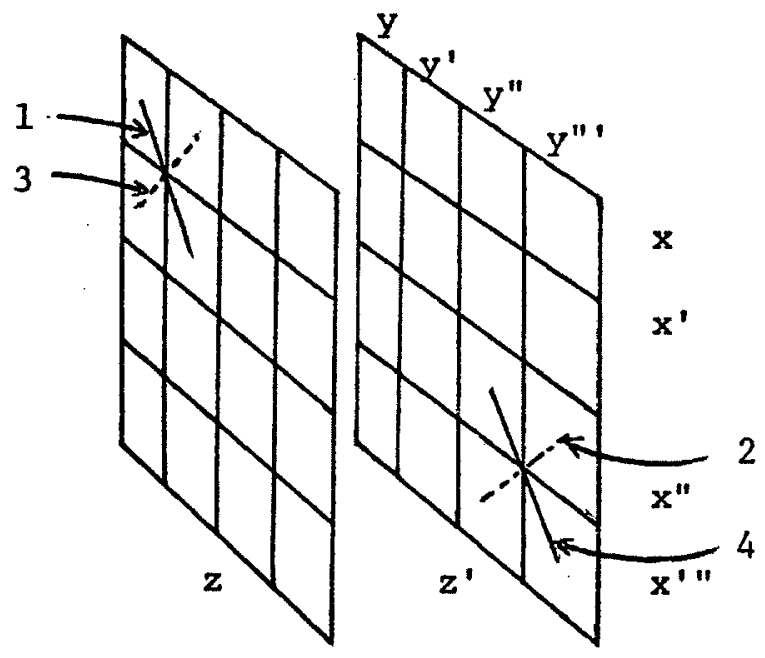

Fig. 3. Distributive cancellation. If the endpoints of diagonal 1 are both greater than the coresponding endpoints of diagonal 2, distributive cancellation is violated when both endpoints of diagonal 4 are greater than the corresponding endpoints of diagonal 3. 
Thus, if the two endpoints of diagonal 1 are respectively greater than the endpoints of diagonal 2, it cannot be the case that both endpoints of diagonal 4 are larger than the respective endpoints of diagonal 3. If the test is failed, and all preceding tests have been passed, we may conclude either that the dual-distributive rule is appropriate, or that no simple polynomial will work.

\section{Dual-distributive Cancellation}

The final test for simple polynomials in the unsigned case is that of dual-distributive cancellation. This is satisfied whenever

$$
\begin{aligned}
\left(x^{\prime \prime}, y^{\prime \prime}, z^{\prime}\right) & \geq\left(x, y^{\prime \prime}, z^{\prime \prime}\right), \\
\left(x^{\prime \prime}, y, z\right) & \geq\left(x^{\prime}, y^{\prime \prime}, z^{\prime \prime}\right), \\
\left(x^{\prime \prime}, y^{\prime \prime}, z^{\prime \prime}\right) & \geq\left(x^{\prime \prime}, y^{\prime \prime}, z^{\prime}\right), \\
\left(x^{\prime \prime}, y^{\prime}, z^{\prime \prime}\right) & \geq\left(x^{\prime \prime}, y^{\prime}, z^{\prime \prime}\right) \\
\text { and }\left(x^{\prime \prime} y^{\prime \prime}, z^{\prime \prime}\right) & \geq\left(x^{\prime \prime}, y^{\prime}, z^{\prime \prime}\right) \\
\text { imply }\left(x^{\prime} y^{\prime}, z^{\prime}\right) & \geq\left(x^{\prime}, y^{\prime}, z^{\prime \prime}\right) .
\end{aligned}
$$

This is clearly the most complex of the testable properties of ordinal data, requiring a high degree of complexity in the levels of attributes. The required $5 \times 5 \times 5$ design includes 125 objects; rank ordering such a matrix is likely to be tedious and unreliable. However, if there are strong a priori reasons to believe the distributive rule is appropriate, and if all tests have been satisfied to that point, then it may not be necessary to attempt to reject the dual-distributive rule. In a study of perceived risk in a series of gambles, Coombs and Huang (1970) concluded that subjects could be characterized with the distributive rule, even 
though they were unable to reject the dual distributive at the level of design they chose.

In summary, it is proposed that polynomial conjoint measurement provides a methodology for the study of judgment that overcomes many of the shortcomings of traditional approaches -- notably the scaling requirements for attribute dimensions and judgments. Using this technique, we may furthermore characterize the strategy of an individual judge, rather than "averaging" judges who may be utilizing entirely different means. Thus it becomes feasible to try to improve judgment strategies by, for example, making simple judgmental strategies more complex.

\section{Purpose}

The purpose of the present study was to demonstrate that the techniques of polynomial conjoint measurement can be applied to the process of human judgment in order to characterize the relationship between information available and the judgments made. In order to demonstrate applicability of this approach, it is necessary to show that judges are sufficiently consistent in their rankings, and that they are transitive in their preferences. The judgment task was designed to maximize the likelihood of a complex decision rule (specifically, the distributive rule); nonetheless, it was felt that the majority of the judges would be characterized adequately by the additive decision rule. 
CHAPTER II

METHOD

\section{Subjects}

The experiment used thirty-two students, all enrolled in an undergraduate course in Industrial Relations at the University of Montana during the Winter Quarter of 1973.

\section{Stimuli}

The stimuli for the experiment were hypothetical applicants for managerial positions, varying in qualifications along the following dimensions: intelligence $(X)$, years of experience in related occupations (Y), and motivation for achievement ( $\mathrm{Z}$ ). Three levels each of $X$ and $Y$, and two levels of $Z$ were used; these are listed in Table 1 . For convenience of design, an additional applicant was included (IQ of 90, no experience, and low motivation), yielding a total of 19 applicants. This task was selected in part because it seemed to increase the likelihood of a complex strategy: it seems plausible that intelligence and experience might combine in an additive fashion to yield basic competency, or ability level; given ability, or what an applicant can do, motivation should determine what he will do. We hypothesized a possible strategy as follows:

$$
\begin{aligned}
\text { Performance } & =\text { motivation } X \text { ability } \\
& =\text { motivation (intelligence }+ \text { experience) }
\end{aligned}
$$


TABLE 1

APPLICANTS TO BE RANKED

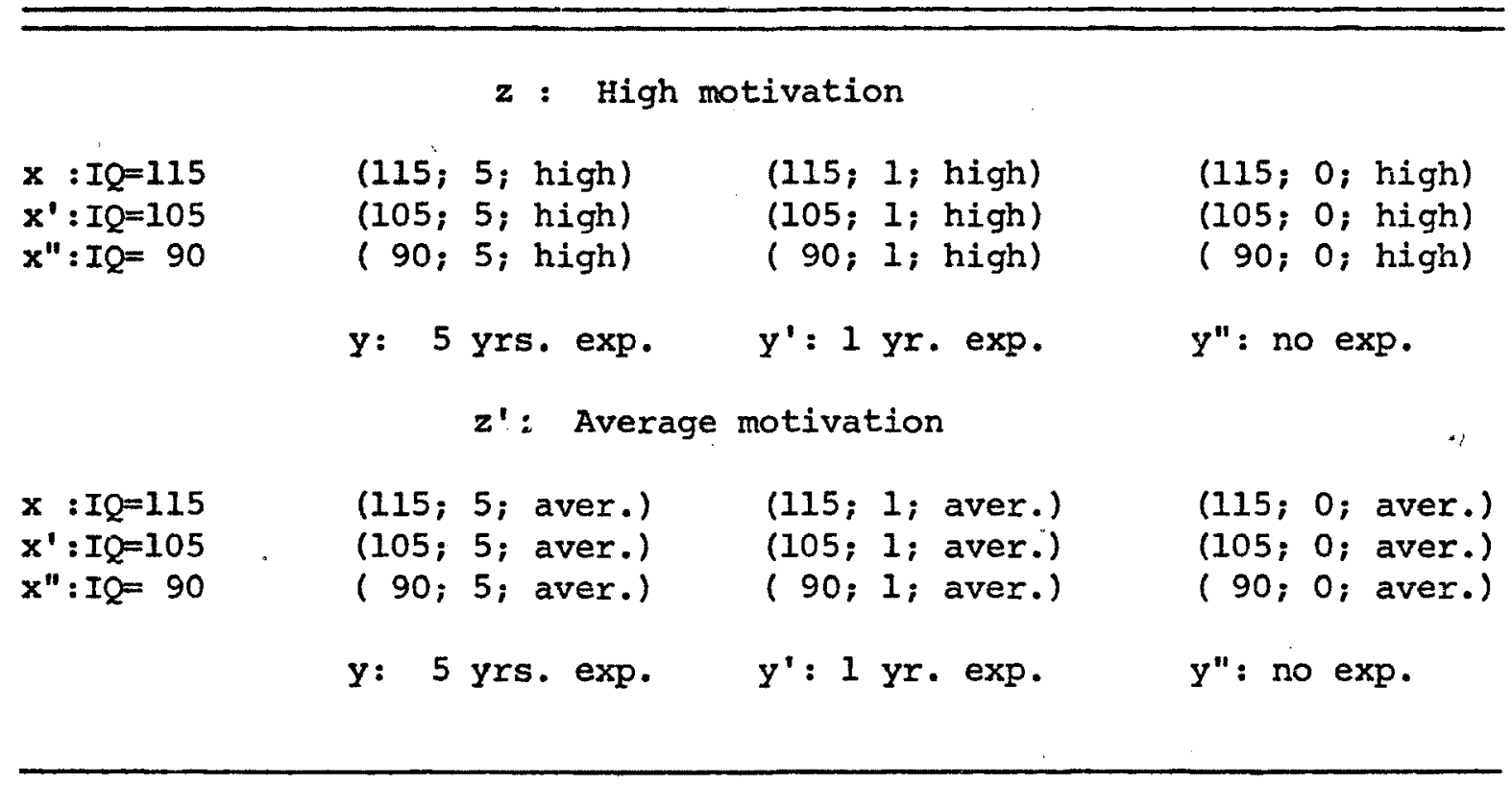


which is equivalent to the distributive rule, $J=(X+Y) Z$. We wished to test the proposition that judges can be interactive in a predictable fashion.

\section{Procedure}

A balanced incomplete blocks design allowed arranging the stimuli into 19 sets of ten applicants each, in which each of the applicants was compared with each of the others exactly five times (Coombs and Huang, 1970). This technique allows an estimate of reliability in giving any judge's consistency in rank ordering; furthermore, it reduces to ten the number of stimuli a judge must handle at one time.

Each applicant's qualifications were printed on individual Hollerith cards, and the cards then arranged into 19 decks of ten cards. Each subject received a complete set of 19 decks and was asked to rank order each deck from most to least desirable for the positions to be filled (see Instructions to the subjects, App. A). Cards were randomized within decks, and the decks given in arbitrary order. The task was performed in class and took between 35 and fifty minutes to complete. 


\section{CHAPTER III}

RESULTS

Treatment of the data

Coombs (1964) discusses several methods of decomposition of unweildy data matrices; the two methods used by Coombs and Huang (1970) were utilized in the present study. They are total vote count (TVC), in which each applicant's rank rests on the sum of applicants over which he was selected in the 19 sortings; and stochastically dominant ordering $(S D O)$, in which the stochastically dominant choice for each pair -- that is, the applicant who was rated over the other 3,4 , or 5 times in the five comparisons -- is scored $I$, and the other, 0 . These orderings are not necessarily the same (although they are identical for the perfectly consistent judge).

The two decompositions provided two $3 \times 3 \times 2$ ordinal matrices for each subject; these were evaluated independently as delineated below.

\section{Consistency. Consistent preference within a pair of applicants} over the five replications of that pairing is a measure of reliability for the judge: if applicant $A$ is preferred to applicant $B$ in all five pairwise comparisons we may infer that, for that judge, there is a discriminable difference between the two stimuli. To assess the degree of consistency in terms of deviation from chance preference, we note that 
distribution of the dominant stimulus in any pair is a folded binomial over 3, 4, and 5. Assuming chance preference, $p(A>B)=\frac{1}{2}$, the mean of the distribution is 3.44 , and the variance is 0.371 . A significant deviation from the chance level for the average over $\left(\begin{array}{r}19 \\ 2\end{array}\right)=171$ pairwise comparisons is thus 3.52. Table 2 lists average consistency for all subjects in decreasing order. As can be seen, consistency is significantly above chance levels; in fact, one subject, number 419, achieved perfect consistency $(5.00)$.

Intransitivity. Transitivity of the form $A>B, B>C \Rightarrow A>C$ is an underlying assumption of an ordinal scale; thus, if it is violated to any appreciable degree, polynomial conjoint measurement is inappropriate as a means for evaluating cue utilization. The assessment of intransitivity in triples proceeds as follows, assuming a 50/50 chance for choice of dominant stimulus. There are eight possible outcomes of dominance relating three stimuli, of which six are transitive and two are intransitive. Thus, $p$ (intransitivity) $=\frac{1}{4}$ for any triple. There are $\left(\begin{array}{c}19 \\ 3\end{array}\right)=969$ sets of triples, resulting in an expected number of intransitive triples for any subject of 242. Total number of intransitive triples using dominant choice is reported in Table 2 . It is apparent that intransitivity is not a problem in the present investigation.

Tests for consistency and transitivity are preliminary to the critical tests to follow. Inconsistency reduces the likelihood that succeeding tests will be satisfied; intransitivity implies that a judge is not operating with an ordinal scale, and negates the theory. 
TABLE 2

CONSISTENCY AND INTRANSITIVITY

\begin{tabular}{|c|c|c|}
\hline Subject No. & Consistency & Intransitivity \\
\hline 419 & 5.000 & 0 \\
\hline 413 & 4.953 & 0 \\
\hline 426 & 4.860 & 2 \\
\hline 424 & 4.860 & 0 \\
\hline 410 & 4.860 & 0 \\
\hline 414 & 4.836 & 2 \\
\hline 405 & 4.825 & 0 \\
\hline 431 & 4.819 & 0 \\
\hline 412 & 4.819 & 1 \\
\hline 411 & 4.813 & 0 \\
\hline 403 & 4.789 & 2 \\
\hline 427 & 4.789 & 0 \\
\hline 420 & 4.784 & 2 \\
\hline 421 & 4.772 & 2 \\
\hline 425 & 4.760 & 2 \\
\hline 409 & 4.754 & 1 \\
\hline 430 & 4.743 & 4 \\
\hline 407 & 4.737 & 4 \\
\hline 415 & 4.731 & 0 \\
\hline 429 & 4.714 & 5 \\
\hline 406 & 4.708 & 4 \\
\hline 416 & 4.702 & 3 \\
\hline 401 & 4.696 & 2 \\
\hline 428 & 4.684 & 1 \\
\hline 404 & 4.684 & 1 \\
\hline 422 & 4.643 & 2 \\
\hline 418 & 4.597 & 3 \\
\hline 432 & 4.585 & 2 \\
\hline 423 & 4.544 & 3 \\
\hline 402 & 4.521 & 0 \\
\hline 408 & 4.515 & 0 \\
\hline 417 & 4.480 & 6 \\
\hline
\end{tabular}


Critical tests

The diagram in Figure 4 reviews the sequence of critical tests in the analysis of composition rules.

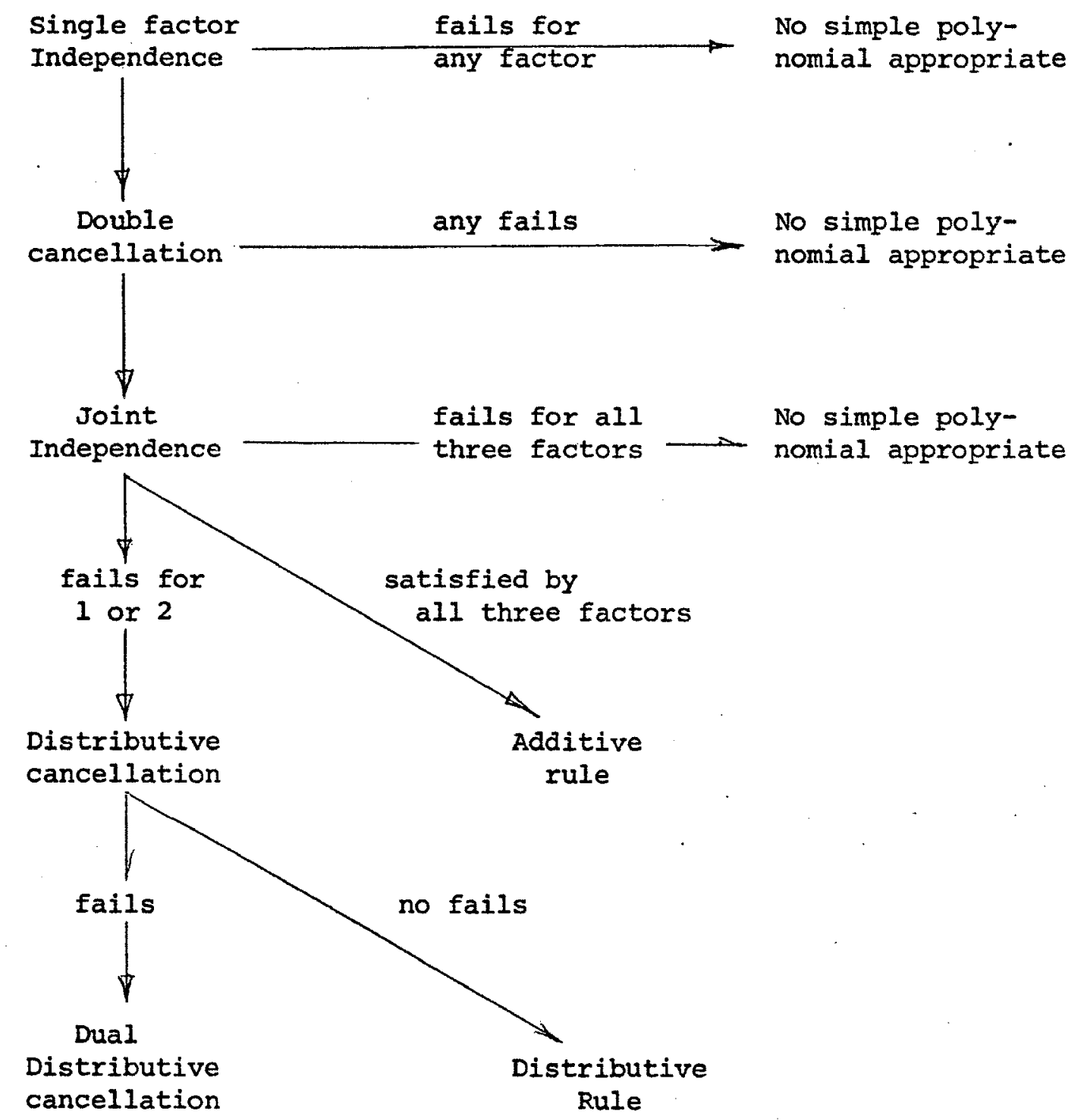

Fig. 4. Sequence of tests in the analysis of composition rules. The series begins in the upper right corner.

As can be seen, single-factor independence and double cancellation must be satisfied completely in order for any of the composition rules to hold. Joint independence serves to distinguish the additive rule. When 
there are failures in joint independence, but no failures in distributive cancellation, the distributive rule will serve. If distributive cancellation is violated, then the dual-distributive rule (or no rule at al1) will serve.

The analysis. of the results follows the sequence implied in Figure 4. Decomposition of the data matrices was carried out by a Fortran IV program written for the DEC system-10. Subsequent tests for polynomial conjoint measurement were performed by a general Fortran IV program entitled PCJM (Ullrich \& Cummins, in press).

Single-factor independence. Coombs and Huang's (1970) notation for independence of one factor with respect to another while the last is held constant provides a convenient method of reference. Independence of $\mathrm{x}$ with respect to $Y$ with $Z$ fixed at $Z$ is coded $X ; Y: Z=Z$, and independence of $X$ with respect to $Y$ with $Z$ fixed at the other level is $X ; Y: Z=Z{ }^{\prime}$.

Testing the independence of $\mathrm{X}$ with respect to $\mathrm{Y}$ involves comparison of the three orderings of $\mathrm{x}$ within a given level of $\mathrm{z}$; all three of these orderings should be the same, although not necessarily the same as they are at the other level of $Z$. This amounts to comparing the $Y$ columns within each $\mathrm{Z}$-plane; thus, at $\mathrm{z}$ there are three orderings that should be the same, and likewise at $z^{\prime}$.

In similar fashion, $Y ; X: Z$ involves comparing the orderings of the $X$ rows in each plane. $Z ; X: Y$ demands comparing the ordering of $Z$ at three levels of $X$ for each of the three levels of $Y$. This corresponds to the property that opposing $z$ entries stand in the same relationship to each other within each $\mathrm{Y}$ column. The test of $\mathrm{Z} ; \mathrm{Y}: \mathrm{X}$ is similar, but compari- 
sons are made within the $x$ rows. Thus, in the latter two cases, there are three subsets of three orderings, which should be the same in each subset.

Kendall's $\tau$ coefficient (Hays, 1963) was used to evaluate the degree of agreement among the rankings for each subject. The $\tau$ coefficient may be defined as follows:

$$
\tau=1-\frac{2 \text { (number of inversions) }}{\text { number of pairs }}
$$

or, equivalently,

$$
\begin{aligned}
& \tau=\text { (number of times rankings) (number of times) } \\
& \text { agree about a pair - rankings disagree }
\end{aligned}
$$

Thus, when there is perfect agreement between rankings, $\tau=1$; if there is complete disagreement, $\tau=-1$; and when there is no tendency for the rankings to agree or to disagree, $\tau=0$.

Average I's were computed for each factor with respect to the others for both stochastically dominant and total vote count orderings. We note that for factors $X$ and $Y$, one inversion in one of the rankings reduces the average $\tau$ to .778 , whereas for $\mathrm{z}$, one inversion results in an average of .556. In the present study, ties were treated as one half.

Table 3 lists average $\tau$ values for single factor independence in order of consistency. Twenty-two of the subjects satisfy the tests perfectly; that is, all six of the average taus are one. Using the less stringent requirement of no more than one reversal in a ranking, we find that a total of twenty-nine of the 32 subjects satisfy single factor independence. 
TABLE 3

TESTS OF SINGLE FACTOR INDEPENDENCE ${ }^{a}$

\begin{tabular}{|c|c|c|c|c|c|c|}
\hline \multirow{2}{*}{$\begin{array}{l}\text { Subject } \\
\text { Number }\end{array}$} & \multicolumn{2}{|r|}{$\begin{array}{c}\text { Factor } \\
\mathrm{X}\end{array}$} & \multicolumn{2}{|c|}{ Factor } & \multicolumn{2}{|c|}{$\begin{array}{c}\text { Factor } \\
\mathbf{Z}\end{array}$} \\
\hline & SDO & TVC & SDO & TVC & SDO & TVC \\
\hline 419 & 1 & 1 & 1 & 1 & 1 & 1 \\
\hline 413 & 1 & 1 & 1 & 1 & 1 & 1 \\
\hline 426 & 1 & 1 & 1 & 1 & 1 & 1 \\
\hline 424 & 1 & 1 & 1 & 1 & 1 & 1 \\
\hline 410 & 1 & .889 & 1 & 1 & 1 & 1 \\
\hline 414 & 1 & 1 & 1 & 1 & .778 & 1 \\
\hline 405 & 1 & 1 & 1 & 1 & 1 & 1 \\
\hline 431 & 1 & 1 & 1 & 1 & 1 & 1 \\
\hline 412 & 1 & 1 & 1 & 1 & 1 & 1 \\
\hline 411 & 1 & 1 & 1 & 1 & 1 & 1 \\
\hline 403 & 1 & 1 & 1 & 1 & 1 & 1 \\
\hline 427 & 1 & 1 & 1 & 1 & 1 & 1 \\
\hline 420 & 1 & 1 & 1 & 1 & 1 & 1 \\
\hline 421 & 1 & 1 & 1 & 1 & 1 & 1 \\
\hline 425 & 1 & 1 & 1 & 1 & 1 & 1 \\
\hline 409 & 1 & 1 & 1 & 1 & 1 & 1 \\
\hline 430 & .800 & 1 & 1 & 1 & 1 & 1 \\
\hline 407 & 1 & 1 & 1 & 1 & 1 & 1 \\
\hline 415 & 1 & 1 & 1 & 1 & 1 & 1 \\
\hline 429 & 1 & 1 & .889 & $I$ & 1 & 1 \\
\hline 406 & 1 & 1 & 1 & 1 & 1 & 1 \\
\hline 416 & 1 & 1 & 1 & 1 & 1 & 1 \\
\hline 401 & 1 & 1 & 1 & 1 & 1 & 1 \\
\hline 428 & 1 & 1 & 1 & 1 & 1 & 1 \\
\hline 404 & 1 & 1 & 1 & 1 & 1 & 1 \\
\hline 422 & 1 & 1 & $(.400)$ & $(.667)$ & 1 & 1 \\
\hline 418 & 1 & 1 & 1 & 1 & .556 & .556 \\
\hline 432 & 1 & 1 & 1 & 1 & 1 & 1 \\
\hline 423 & 1 & 1 & 1 & .778 & 1 & 1 \\
\hline 402 & 1 & $(.556)$ & 1 & 1 & 1 & 1 \\
\hline 408 & 1 & .778 & 1 & 1 & 1 & 1 \\
\hline 417 & .778 & $(.422)$ & 1 & 1 & 1 & 1 \\
\hline
\end{tabular}

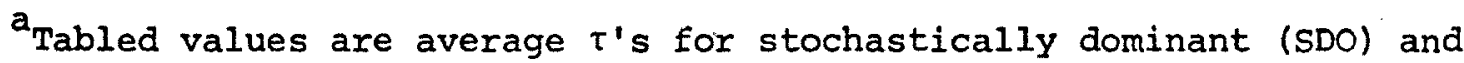
total vote count (TVC) orderings. Values in parentheses represent a violation of the test, i.e., more than one reversal in one of the orderings. 
Double cancellation. When single-factor independence has been established for a given judge, the next critical test is double cancellation. This test requires at least a $3 \times 3$ submatrix in a given plane; thus it was performed only in XxY at each level of $\mathrm{z}$. Only one subject, number 404, had a failure in double cancellation.

Joint independence. As stated above, joint independence must be satisfied for all pairs of factors for the additive rule to hold; however, it need not be satisfied by all pairs of factors in the distributive or dual-distributive cases. For example, if we hypothesize the composition rule $(X+Y) Z$, then factors $X$ and $Y$ must satisfy joint independence with respect to $Z$, since the ordering imposed by them will be invariant over levels of $z$. On the other hand, $X X Z: Y$ and $Y X Z: X$ may violate joint independence, since the orderings will depend on the levels chosen. Average $\tau$ 's for each ordering are listed in Table 4; Table 5 summarizes tests for joint independence. One reversal in one ordering is again taken as the minimum success criterion; for $\mathrm{XXY}: \mathrm{Z}$ this results in a value of .944 , while a reversal in $\mathrm{XXZ}: \mathrm{Y}$ or $\mathrm{YxZ}: \mathrm{X}$ results in an average $\tau$ of .911.

From Table 4, it is evident that three subjects satisfy joint independence perfectly for all pairs of factors, and an additional eleven satisfy the tests with no more than one reversal in an ordering. These fourteen may be characterized as using an additive strategy. of those satisfying the preliminary tests, an additional six subjects show interaction (i.e., failures of joint independence) in one or two pairs of factors, with both decompositions. One subject, number 418 , appears to 
TABLE 4

TESTS OF JOINT INDEPENDENCE ${ }^{a}$

\begin{tabular}{|c|c|c|c|c|c|c|}
\hline \multirow{2}{*}{$\begin{array}{l}\text { Subject } \\
\text { Number }\end{array}$} & \multicolumn{2}{|c|}{$X X Y: Z$} & \multicolumn{2}{|c|}{$X X Z: Y$} & \multicolumn{2}{|c|}{$Y X Z: X$} \\
\hline & SDO & TVC & SDO & TVC & SDO & TVC \\
\hline $419 * *$ & 1 & 1 & 1 & 1 & 1 & 1 \\
\hline $413 * \star$ & 1 & 1 & 1 & 1 & 1 & 1 \\
\hline 426 ** & .972 & .944 & .933 & .911 & .933 & .956 \\
\hline $424 * *$ & .944 & 1 & 1 & 1 & .911 & .911 \\
\hline $410 *$ & 1 & .972 & 1 & .956 & 1 & 1 \\
\hline $405 * *$ & 1 & 1 & .911 & 1 & 1 & 1 \\
\hline $431 * *$ & 1 & 1 & 1 & 1 & 1 & 1 \\
\hline $411 * *$ & .944 & .972 & .911 & .911 & 1 & .956 \\
\hline $403 * *$ & .944 & .944 & .933 & 1 & .911 & .911 \\
\hline $420 * *$ & 1 & 1 & 1 & 1 & .911 & 1 \\
\hline $421 *$ * & 1 & 1 & .956 & .911 & .911 & .956 \\
\hline $409 * *$ & $(.917)$ & $(.889)$ & 1 & 1 & $(.867)$ & $(.822)$ \\
\hline $407 * *$ & .944 & 1 & .956 & 1 & .911 & .911 \\
\hline 415 ** & .944 & $(.917)$ & 1 & .911 & .911 & .911 \\
\hline $406 * *$ & .944 & .972 & .911 & 1 & .911 & .911 \\
\hline $401 * *$ & 1 & 1 & .911 & .956 & 1 & 1 \\
\hline $427 * *$ & .944 & $(.917)$ & 1 & 1 & 1 & 1 \\
\hline $425 * *$ & 1 & .972 & 1 & 1 & $(.822)$ & .911 \\
\hline $423 *$ & .972 & $(.889)$ & 1 & 1 & 1 & .911 \\
\hline $429 *$ & .917 & 1 & .911 & .911 & $(.889)$ & .933 \\
\hline $4.14^{*}$ & $(.889)$ & $(.917)$ & .956 & 1 & $(.822)$ & $(.867)$ \\
\hline $412 * *$ & $(.861)$ & $(.889)$ & .956 & $I$ & $(.867)$ & .911 \\
\hline 428 ** & $(.861)$ & $(.833)$ & .911 & .911 & $I$ & $I$ \\
\hline $404^{b}$ & $(.861)$ & $(.833)$ & 1 & 1 & 1 & 1 \\
\hline $418 *$ & $(.861)$ & .972 & $(.822)$ & $(.822)$ & $(.644)$ & $(.733)$ \\
\hline 432 ** & $(.861)$ & $(.889)$ & .956 & .911 & 1 & .956 \\
\hline $408 *$ & 1 & $(.917)$ & .911 & $(.733)$ & 1 & .956 \\
\hline $416 * *$ & $(.861)$ & .944 & .911 & 1 & $(.822)$ & $(.822)$ \\
\hline $430 *$ & $(.917)$ & 1 & $(.889)$ & 1 & $(.822)$ & .911 \\
\hline 402 & .944 & $(.722)$ & 1 & $(.822)$ & 1 & .911 \\
\hline 417 & $(.889)$ & $(.778)$ & .911 & $(.733)$ & .911 & .911 \\
\hline 422 & $(.833)$ & $(.917)$ & $(.867)$ & .911 & $(.756)$ & $(.867)$ \\
\hline
\end{tabular}

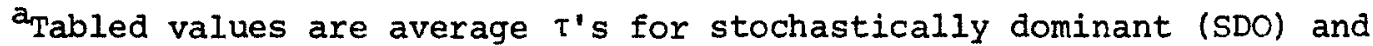
total vote count (IVC) orderings. Values in parentheses represent failure of the test, i.e., more than one reversal in one of the orderings.

bailure in double cancellation

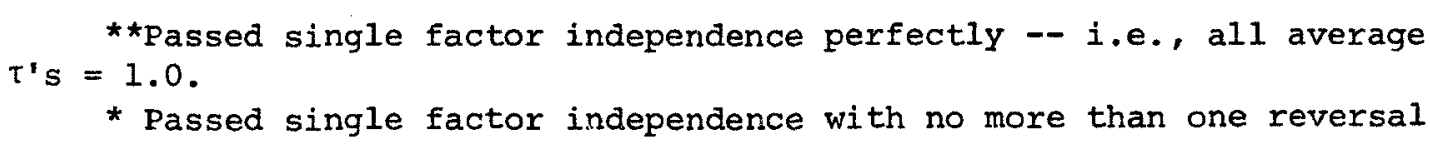


fail joint independence for all three pairs of factors; thus, no simple polynomial is appropriate. Interpretation for the others is more difficult because failures occur in only one of the two orderings. For example, subjects 427 and 423 fail joint independence only in the total vote count ordering for one pair of factors; thus, an additive composition rule could be found that would generate the proper ordinal structure for their stochastically dominant orderings, while a distributive rule would be necessary to account for their total vote count orderings. It is probably most parsimonious (and conservative) to assume that the failure is a result of carelessness in sorting, and to conclude that an additive rule would suffice.

If a judge satisfies plane independence but fails joint independence in one or two pairs of factors, then both the distributive rule and the dual-distributive rule remain as possibilities. Thus, the next critical test is distributive cancellation.

Distributive cancellation. In order to test distributive cancellation, three antecedents must be satisfied [12]; thus, the number of tests for an individual depends on how he ranked the applicants. Of the six subjects failing joint independence with respect to at least one pair of factors, three have no failures of distributive cancellation; another has only one failure in twenty tests for both rankings. These four may be considered adequately characterized by the distributive rule. The remainder show failures of distributive cancellation, and thus might be characterized by the dual distributive rule. (It should be recalled that the levels of the present study do not allow us to settle conclusively on the dual distributive rule.) 
TABLE 5

SUMMARY OF TESTS OF JOINT INDEPENDENCE

\begin{tabular}{|c|c|c|c|c|c|c|c|c|c|c|}
\hline & & \multicolumn{3}{|c|}{ XXY: Z } & \multicolumn{3}{|c|}{$X x Z: Y$} & \multicolumn{3}{|c|}{ YXZ:X } \\
\hline & & $\tau \geq$ & .944 & $\tau=1$ & $\tau \geqq$ & .911 & $\tau=1$ & $\tau \geqslant$ & .911 & $\tau=1$ \\
\hline All subjects & $S D O^{a}$ & & 20 & 10 & & 29 & 13 & & 23 & 14 \\
\hline$\underline{N}=32$. & $T V C^{b}$ & & 19 & 11 & & 28 & 18 & & 27 & 10 \\
\hline Subset & SDC & & 19 & 10 & & 26 & 11 & & 20 & 12 \\
\hline of $27^{c}$ & TVC & & 18 & 11 & & 26 & 17 & & 24 & 9 \\
\hline
\end{tabular}

$a_{\text {SDO }}=$ stochastically dominant ordering.

$b_{\text {TVC }}=$ total vote count ordering.

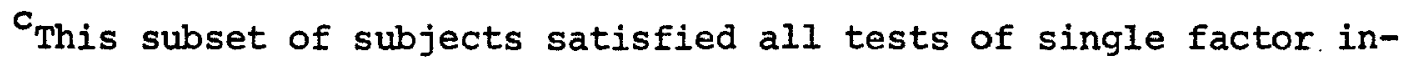
dependence with no more than one reversal in an ordering. 
TABLE 6

SUMMARY OF POLYNOMIAL CONJOINT MEASUREMENT TESTSa

\begin{tabular}{|c|c|c|c|c|c|c|c|c|c|c|c|c|c|}
\hline \multirow{3}{*}{$\begin{array}{l} \\
\text { so. } \\
\text { No. }\end{array}$} & \multicolumn{5}{|c|}{ Single Factor Independence } & \multicolumn{8}{|c|}{ Joint Independence } \\
\hline & \multicolumn{2}{|r|}{$\mathrm{X}$} & \multicolumn{2}{|r|}{$\mathrm{Y}$} & \multicolumn{2}{|c|}{$\mathrm{z}$} & \multicolumn{2}{|c|}{$X X Y: Z$} & \multicolumn{2}{|c|}{$X X Z: Y$} & \multicolumn{2}{|c|}{$Y x Z: X$} & \multirow{2}{*}{$\begin{array}{l}\text { Dist } \\
\text { Can. }\end{array}$} \\
\hline & SDO & TVC & SDO & IVC & SDO & TVC & SDO & TVC & SDO & TVC & SDO & TVC & \\
\hline & \multicolumn{13}{|c|}{ ADDITIVE } \\
\hline 419 & 1 & 1 & 1 & 1 & 1 & 1 & 1 & 1 & 1 & 1 & 1 & 1 & $0: 0$ \\
\hline 413 & 1 & 1 & I & 1 & 1 & 1 & 1 & 1 & 1 & 1 & 1 & 1 & $0: 0$ \\
\hline 426 & 1 & 1 & 1 & 1 & 1 & 1 & .972 & .944 & .933 & .911 & .933 & .956 & $38: 0$ \\
\hline 424 & 1 & 1 & 1 & 1 & 1 & 1 & .944 & 1 & 1 & 1 & .911 & .911 & $18: 0$ \\
\hline 410 & 1 & .889 & 1 & 1 & 1 & 1 & 1 & .972 & 1 & .956 & 1 & 1 & $12: 0$ \\
\hline 405 & 1 & 1 & 1 & 1 & 1 & 1 & 1 & 1 & .911 & 1 & 1 & 1 & $20: 0$ \\
\hline 431 & 1 & 1 & 1 & 1 & 1 & 1 & 1 & 1 & 1 & 1 & 1 & 1 & $0: 0$ \\
\hline 411 & 1 & 1 & 1 & 1 & 1 & 1 & .944 & .972 & .911 & .911 & 1 & .956 & $28: 0$ \\
\hline 403 & 1 & 1 & 1 & 1 & 1 & 1 & .944 & .944 & .933 & 1 & .911 & .911 & $50: 1$ \\
\hline 420 & 1 & 1 & 1 & 1 & 1 & 1 & 1 & 1 & 1 & 1 & .911 & 1 & $50: 1$ \\
\hline 421 & 1 & 1 & 1 & 1 & 1 & 1 & 1 & 1 & .956 & .911 & .911 & .956 & $25: 0$ \\
\hline 407 & 1 & 1 & 1 & 1 & 1 & 1 & .944 & 1 & .956 & 1 & .911 & .911 & $22: 0$ \\
\hline 406 & 1 & 1 & 1 & 1 & 1 & 1 & .944 & .972 & .911 & 1 & .911 & .911 & $40: 1$ \\
\hline \multirow[t]{2}{*}{401} & 1 & 1 & 1 & 1 & 1 & 1 & 1 & 1 & .911 & .956 & 1 & 1 & $40: 0$ \\
\hline & \multicolumn{13}{|c|}{ POSSIBLY ADDITIVE } \\
\hline 427 & 1 & 1 & 1 & 1 & 1 & 1 & .944 & $(.917)$ & 1 & 1 & 1 & 1 & $16: 0$ \\
\hline 415 & 1 & 1 & $I$ & 1 & 1 & 1 & .944 & $(.917)$ & 1 & .911 & .911 & .911 & $34: 0$ \\
\hline 425 & 1 & 1 & 1 & 1 & 1 & 1 & 1 & .972 & 1 & 1 & $(.822)$ & .911 & $39: 1$ \\
\hline 423 & 1 & 1 & 1 & .778 & 1 & 1 & .972 & $(, 889)$ & 1 & 1 & 1 & .911 & $4: 0$ \\
\hline \multirow[t]{2}{*}{429} & 1 & 1 & .889 & 1 & 1 & 1 & $(.917)$ & 1 & .911 & .911 & $(.889)$ & .933 & $26: 0$ \\
\hline & \multicolumn{13}{|c|}{ DISTRIBUTIVE } \\
\hline 414 & 1 & 1 & 1 & 1 & .778 & 1 & $(.889)$ & $(.917)$ & .956 & 1 & $(.822)$ & $(.867)$ & $62: 1$ \\
\hline 412 & 1 & 1 & 1 & 1 & 1 & 1 & $(.861)$ & $(, 889)$ & .956 & 1 & $(.867)$ & .911 & $36: 0$ \\
\hline 428 & 1 & 1 & 1 & 1 & 1 & 1 & $(.861)$ & $(.833)$ & .911 & .911 & 1 & 1 & $24: 0$ \\
\hline \multirow[t]{2}{*}{432} & 1 & 1 & 1 & 1 & 1 & 1 & $(.861)$ & $(.889)$ & .956 & .911 & 1 & .956 & $18: 0$ \\
\hline & \multicolumn{13}{|c|}{ DUAL DISTRIBUTIVE } \\
\hline 416 & 1 & 1 & 1 & 1 & 1 & 1 & $(.861)$ & .944 & .911 & 1 & $(.822)$ & $(.822)$ & $40: 4$ \\
\hline \multirow[t]{2}{*}{409} & 1 & 1 & 1 & 1 & 1 & 1 & $(.917)$ & $(.889)$ & 1 & 1 & $(.867)$ & $(.822)$ & $52: 2$ \\
\hline & \multicolumn{13}{|c|}{ FAIL SINGLE FACTOR INDEPENDENCE } \\
\hline 422 & 1 & 1 & $(.400)$ & $(.667)$ & 1 & 1 & $(.833)$ & $(.917)$ & $(.867)$ & .911 & $(.756)$ & $(.867)$ & $29: 1$ \\
\hline 402 & 1 & $(.556)$ & 1 & 1 & 1 & 1 & .944 & $(.722)$ & 1 & $(.822)$ & 1 & .911 & $0: 0$ \\
\hline \multirow[t]{2}{*}{417} & .778 & $(.422)$ & 1 & 1 & 1 & 1 & $(.889)$ & $(.778)$ & .911 & $(.733)$ & .911 & .911 & $15: 0$ \\
\hline & & & FAILS & JOINT & INDEPE & ENCE & ALL THF & EEE PAIR & RS OF F & ACTORS & & & \\
\hline \multirow[t]{2}{*}{418} & 1 & 1 & 1 & 1 & .556 & .556 & $(.861)$ & .972 & $(.822)$ & $(.822)$ & $(.644)$ & $(.733)$ & $42: 0$ \\
\hline & & & & & FAILURE & N DO & E CANCEI & LATION & & & & & \\
\hline 404 & 1 & 1 & 1 & 1 & 1 & 1 & $(.861)$ & $(.833)$ & 1 & 1 & 1 & 1 & $0: 0$ \\
\hline & & & & & & GMEN & ITHHELD & & & & & & \\
\hline 430 & .800 & 1 & 1 & 1 & 1 & 1 & $(.917)$ & 1 & $(, 889)$ & 1 & $(.822)$ & .911 & $56: 1$ \\
\hline 408 & 1 & .778 & 1 & 1 & 1 & i & 1 & $(.917)$ & 911 & $(.733)$ & 1 & .956 & $24: 0$ \\
\hline
\end{tabular}

${ }^{a_{T}}$ Tabled values are average $T$ 's for stochastically dominant (SDO) and total vote count (TVC) orderings. Values in parentheses represent failures at the one-reversal criterion.

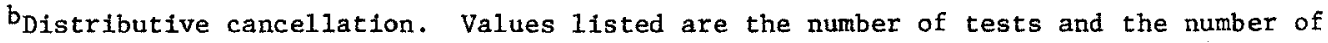
failures, respectively. 
Table 6 summarizes critical tests; subjects are arranged into groups by most likely composition rule. Test failures are enclosed in parentheses for ease of reference. Fourteen subjects are clearly additive; an additional five are classified "possibly additive." This classification seems justified because for one of the decompositions an additive rule would suffice, and the failures in joint independence in the other ordering are not large. Four subjects are classified distributive; there are two who might be characterized by the dual distributive rule (or by no simple polynomial). Three subjects fail single factor independence, another fails double cancellation, and another appears to fail joint independence for all three pairs of factors. Judgment is withheld on two subjects because of the major discrepancies between the two compositions. 
CHAPTER IV

\section{DISCUSSION}

Table 7 summarizes conclusions about types of composition rules that might best characterize the sample of judges. It appears that about seventy per cent of the subjects for whom a simple polynomial is appropriate are best described by an additive rule; that is, their judgments rest on a sum of appropriately weighted measures of intelligence, experience, and motivation. This finding is consonant with considerable research, mentioned above, which suggest that human judges tend overwhelmingly to be additive (linear).

The observed interactive strategies are of substantive interest as well. Table 6 suggests that most judges classified distributive (as well as those who might be dual distributive) fail joint independence in $\mathrm{XXY}$ and $\mathrm{YXZ}$. Such a pattern is consistent with the distributive rule $Y(X+Z)$. Thus, the joint effect that intelligence and motivation have on the final judgment depends on the amount of experience. It will be recalled that the hypothesized distributive strategy was $(X+Y) Z$. Even independently of weights assigned by different judges, the obtained strategy places considerable emphasis on experience. This may be due to a manipulation in the instructions (Appendix A), a statement that applicants were expected to stay in the job only two or three years, thereby increasing the salience of the experience dimension. Increased salience 
can be equivalent to merely increasing the weighting coefficient; however, distributive subjects in this case use the dimension in a pivotal or defining fashion. The meaning of such an interaction might be interpreted as follows: "I prefer individual A to individual $B$ when both have no experience. "However, if they both have one or five years" experience, I prefer individual B to individual A." This is clearly a more complex strategy, and its outcome can be quite different from that of an additive strategy.

Several methodological and theoretical conclusions also deserve mention. Orly five of thirty-two subjects seem to be operating in a fashion that absolutely cannot be described by a simple polynomial in three variables. Thus, a formal relational system of some precision and generality may be defined upon a sequence of (non-numerical) preferential judgments, whereby the empirical observation "is preferred or indifferent to" is replaced by the mathematical symbol " $\geqslant$ " On the basis of this obtained relational system, it is possible to scale attribute and judgment dimensions for the individual judge, using existing computer algorithms (e.g., Kruskal, 1965; Tversky and Zivian, 1966). Of somewhat greater significance, however, are the following observations: (a) an indication of configurality or linearity in the judgment process may be obtained without making a series of assumptions concerning distributions underlying dimensions of interest; and (b) such assessment can be made for the individual judge. Most traditional approaches would probably miss the subset of configural judges for two reasons: first, most such techniques rely on pooling data across individuals (partly in order to 
TABLE 7

SUMMARY OF COMPOSITION RULES ${ }^{a}$

\begin{tabular}{lccc}
\hline \hline & $\begin{array}{c}\text { Number of } \\
\text { judges }\end{array}$ & $\begin{array}{c}\text { Tentatively } \\
\text { assigned }\end{array}$ & Total \\
Rule & 14 & 5 & 19 \\
Additive & 4 & 5 \\
$\begin{array}{l}\text { Distributive } \\
\text { Dual distributive }{ }^{\text {a }}\end{array}$ & $\frac{2}{20}$ & 5 & $\frac{2}{25}$ \\
& Failures & 3 \\
Failed single factor independence & 1 \\
Failed joint independence on all three pairs & $\frac{1}{5}$ \\
Failed double cancellation &
\end{tabular}

Judgment withheld due to disagreement between $S D O^{b}$ and $T^{\mathrm{C}} \mathrm{C}^{\mathrm{C}} \quad 2$

The levels of the present study make it impossible to determine whether the dual distributive rule may hold, or whether no simple polynomial is appropriate.

${ }^{b}$ SDO $=$ The stochastically dominant ordering.

$C_{\text {TVC }}=$ The total vote count ordering. 
make tenable the assumption of normality for tests of significance); and second, linear regression techniques in particular have so much power that they tend to obscure interactive relationships (Anderson, 1972). The usefulness of the present technique in the study of judgment depends on its generality across tasks, and certainly to some extent upon the empirical accuracy of the composition rules. If we find that additivity is constant within individuals across situations -- i.e., that an additive judge is always additive -- and that some important sorts of judgments require configural strategies, then it would be worthwhile to try to train judges in configural strategies. A related question is whether, having learned to utilize a distributive composition rule in one task, a juage will try a more complex strategy in a different series -for example, one involving four or more attribute dimensions -- or whether he will revert to his old additive strategy.

It should be kept in mind that the evidence for configurality of judgment is not strong -- by far the more convincing evidence is that for additivity. The average $\tau$ 's that led us to settle on a distributive rule for some subjects are not dramatically below the arbitrary cutoff in most cases; nonetheless, the suggestion of the data is that a distributive composition rule would do better in reconstituting the observed ordinal matrices. Furthermore, the tendency toward configurality in judges appears to be a weak one, even in research which encourages it more than does the present study (e.g., Hoffman, Slovic, and Rorer, 1968). For these reasons, we are willing to accept the evidence tentatively; it would be instructive to identify a subset of configural judges, and to 
test the hypothesis of configurality with a series of differently constituted tasks. Subjective evaluation research provides a different mode of judgment, and has already shown a predominance of additivity (Green, Carmone, and Wind, 1972); combinations of adjectives evaluated in terms of "likability" might be another (McClelland, 1972; Anderson, 1962). If the tendency toward configurality or additivity of judgmental strategy seems constant, then research in the efficacy of different strategies and study of the process of modifying strategies are strongly indicated. 


\section{CHAPTER V}

\section{SUMMARY}

Rank-order preferences were obtained for a series of hypothetical job applicants varying simultaneously on three attribute dimensions: intelligence, experience, and motivation. The resulting ordinal matrices were analyzed by polynomial conjoint measurement techniques; 80 per cent of the subjects could be characterized by the method; of those, 70 per cent were additive, about 15 per cent were declared configural, and judgment was withheld on the remainder. It was concluded that polynomial conjoint measurement can be sensitive to linearity and configurality in preferential judgment tasks. 
REFERENCES

Allport, G. W. The use of personal documents in psychological science. S.R.R.C. Bulletin No. 49, 1942. Cited in P. E: Meehl, Clinical versus statistical prediction: A theoretical analysis and a review of the evidence. Minneapolis: University of Minnesota Press, 1954.

Anderson, N. H. Application of an additive model to impression formation. Science, $1962,138,817-818$.

Anderson, N, H. A simple model for information integration. In R. P. Abelson, E. Aronson, and W. McGuire (Eds.), Cognitive consistency: A sourcebook. Chicago: Rand McNa11y, 1968 .

Anderson, N. H, Integration theory and attitude change. Psychologica1 Review, 1971, 78, 171-202.

Anderson, N. H. Looking for configurality in clinical judgment. Psychological Bulletin, 1972, 78, 93-102.

Coombs, C. H. A theory of data. New York: John Wiley \& Sons, 1964.

Coombs, C. H., Dawes, R. M., and Tversky, A. Mathematical psychology: An elementary introduction. Englewood Cliffs, N.J.: Prentice-Ha11, 1970.

Coombs, C. H. and Huang, L. C. Polynomial psychophysics of risk. Journal of Mathematical Psychology, 1970, 7, 317-338.

Green, P. E., Carmone, F. J., and Wind, Y. Subjective evaluation models and conjoint measurement. Behavioral Science, 1972, 17, 288-299.

Harrison, R. The TAT and Rorschach methods of personality investigation in clinical practice, Journal of Psychology, 1943, 15, 49-74.

Hays, W. L. Statistics. New York: Holt, Rinehart, and Winston, 1963.

Hoffman, P. J. The paramorphic representation of clinical judgment. Psychological Bulletin, 1960, 57 (2), 116-131.

Hoffman, P. J., Slovic, P, and Rorer, L. G. An analysis-of-variance model for the assessment of configural cue utilization in clinical judgment. Psychological Bulletin, 1968, 69, $338-349$. 
Hursch, C. J., Hammond, K. R., and Hursch, J. Some methodological issues in multiple-cue probability studies. Psychological Review, 1964, 71, 42-60.

Kirk, S. A. and Kirk, W. D. Psycholinguistic learning disabilities: Diagnosis and remediation. Urbana, I11.: University of Illinois Press, 1971.

Krantz, D. H., Luce, R. D., Suppes, P., and Tversky, A. Foundations of measurement. New York: Academic Press, 1971. 2 vols.

Krantz, D. H. and Tversky, A. Conjoint-measurement analysis of composition rules in psychology. Psychological Review, 1971, 78, $151-169$.

Kruskal, J. B. Analysis of factorial experiments by estimating monotone transformations of the data. Journal of the Royal Statistical Society, Series B., 1965, 27, 251-263.

Martin, H. T., Jr. The nature of clinical judgment. Unpublished doctoral dissertation, Washington State College, 1957. Cited in P. J. Hoffman, The paramorphic representation of clinical judgment. Psychological Bulletin, 1960, 57, 116131 .

McClelland, G. H. Non-metric tests of composition rules in impression formation. Michigan Mathematical Psychology Program Technical Report, MMPP 72-7, University of Michigan, 1972.

Meeh1, P. E. Clinical versus statistical prediction: A theoretical analysis and a review of the evidence. Minneapolis: University of Minnesota Press, 1954.

Sidowski, J. B. and Anderson, N. H. Judgments of city-occupation combinations. Psychonomic Science, 1967, 7, 279-280.

Tversky, A. and Zivian, A. A. A computer program for additivity analysis. Behavioral Science, $1966,11,78-79$.

Ullrich, J. R. and Cummins, D. E. PCJM: A program for conjoint measurement analysis of polynomial composition rules. Subn mitted for publication February, 1973.

Wiggins, N. L., and Hoffman, P. J. Three models of clinical judgment. Journal of Abnormal Psychology, 1968, 73, 70-77. 
APPENDIX A

\author{
INSTRUCTIONS
}

Imagine that you are a personnel manager for a large corporation. You must review many applicants for managerial and foreman positions; since the openings often cannot be foreseen, your task is to rank order the applicants from most to least desirable for your company. People usually keep these jubs only two or three years, so "break-in" time is a consideration. You must make your rankings on the basis of the following information:

Motivation.

High: values success highly; greatly desires promotion and recognition. Willing to sacrifice leisure time in order to get ahead. Average: values doing a satisfactory job, but not as inclined as high subjects to make sacrifices. "Success" and promotion not critical to his happiness.

Low: not concerned about what his superiors think; tries to do just enough to get by.

Intelligence.

IQ (intelligence quotient) may be regarded as an estimate of the applicant's ability to learn--his ability to pick up new information quickly, and to grasp abstract concepts and ideas. It is also closely related to his verbal ability.

115: high intelligence: learns quickly, sees abstract relationships readily; likely to come up with new and innovative ideas; probably good with language.

105: slightly above average intelligence; picks up new ideas without too much trouble; not quite as likely as 115 to see abstract ideas; will occasionally come up with original ideas.

90 ; slightly below average intelligence; learns new ideas

with a little difficulty, requiring somewhat more repetition; not likely to come up with innovative ideas; probably not as good with written or spoken language.

Years of experience in related occupations. job.

This category implies experience in a managerial or supervisory

The information for each applicant is printed on a single card. Your task is to rank order these applicants in groups of ten, placing the most desirable applicant first (on the top of the deck), and the least desirable last. Please work carefully, and insure for every applicant 
that you prefer him to the one below him and that he is 1ess desirable than the one above him.

You have nineteen of these groups of ten; please do the groups one at a time, and put the rubber band on each when you have finished. 